\title{
Sobre as Bases Videográficas (ou Cinematográficas) da Língua Brasileira de Sinais
}

On the videographic (or cinematographic) bases of the Brazilian Sign Language Marcelo Santos - Faculdade Cásper Líbero | São Paulo | SP | Brasil | E-mail:
masmoraes@casperlibero.edu.br | https://orcid.org/0000-0003-4599-9885

Resumo: Este artigo sugere que a noção de cinematografia, concebida por Sergei Eisenstein como "montagem", a combinação de cenas que são representativas, de significado único e neutras em conteúdo, em contextos e séries intelectuais, através das quais se consegue produzir um "cinema intelectual", talvez seja base para pensar não apenas o cinema em seus próprios termos, mas também as línguas de sinais, cujo princípio semiótico, eis a hipótese de trabalho, é o mesmo do cinema eisensteiniano. Inicialmente, examina-se a noção de ideograma, signos figurativos não fonéticos criados para representar existentes ou ideias. $\mathrm{Na}$ sequência, fala-se do ideograma como base do cinema de Eisenstein e de como este mesmo alicerce parece importante para se refletir sobre a Língua Brasileira de Sinais, inclusive sobre o seu registro.

Palavras-chave: Cinema. Eisenstein. Ideograma. LIBRAS. Linguagem.

Abstract: In this article we suggest that the notion of cinematography, coined by Sergei Eisenstein as "montage", the combination of scenes that are representative, of unique meaning and content neutral, in intellectual contexts and series, is perhaps the basis for thinking not only of cinema on its own terms, but also of sign languages, whose semiotic principle is the same as that of Eisensteinian cinema. This is our working hypothesis. Initially, we examine the notion of ideogram, nonphonetic figurative signs created to represent existents or ideas. In the next section, we discuss the ideogram as the basis of Eisenstein's cinema, and we point out how this foundation seems important to reflect on the Brazilian Sign Language, including the way it is recorded.

Keywords: Cinema. Eisenstein. Ideogram. LIBRAS. Language.

- Recebido em: 13 nov. 2019 • Aprovado em: 05 dez. 2019 • e-ISSN: 2177-5788

DOI: https://doi.org/10.22484/2177-5788.2019v45n2p429-444

Copyright @ 2019. Conteúdo de acesso aberto, distribuído sob os termos da Licença Internacional da CreativeCommons - CC BY-NC-SA - Atribuição Não Comercial (https://br.creativecommons.org/licencas/) - Permite distribuição e reprodução, desde que atribuam os devido créditos à publicação, ao autor(es) e que licenciem as novas criações sob termos idênticos. 


\section{Introdução}

Apenas no ano de 1984, a Organização das Nações Unidas para a Educação, a Ciência e a Cultura (UNESCO) reconheceu formalmente as línguas de sinais como sistemas de comunicação legítimos análogos a outras línguas. O fato não causa estranheza: existe nos estudos linguísticos certo fonologocentrismo, aquilo denunciado por Jacques Derrida (1973) em sua "Gramatologia" como a tendência de associar, no Ocidente, phoné (som), glossa (significado) e logos (pensamento), isto é, a razão ou a racionalidade à fala - e, consequência direta, a surdez e a afasia à debilidade mental. Daí a equiparação, na sociedade grega, dos surdos aos animais; ou a concepção ainda hoje vigente de que o surdo, conforme Skliar (1997), para humanizar-se, precisa ser oralizado.

Sigamos com Derrida (1973, p. 63); o filósofo francês, também na "Gramatologia", arrola as obras de Aristóteles, Descartes, Rousseau, Hegel e Saussure, ou ainda "toda a filosofia ocidental", como sintoma desta cultura fonologocêntrica, um projeto civilizatório referendado por ninguém menos que o Espírito Santo:

A escritura natural está imediatamente unida à voz e ao sopro. Sua natureza não é gramatológica, mas pneumatológica. É hierática, bem próxima da santa voz interior da Profissão de Fé, da voz que se ouve ao se entrar em si: presença plena e veraz da fala divina a nosso sentimento interior (DERRIDA, 1973, p. 21).

De modo que se Evangelho de João (BÍBLIA, 1969) não nos deixa dúvidas sobre a natureza semiótica da criação - "No princípio, era o Verbo, e o Verbo estava com Deus, e o Verbo era Deus" (JOÃO 1:1) -, ele também sentencia que a palavra de Deus, questão sensorial, é acústica: "As minhas ovelhas ouvem a minha voz; eu as conheço, e elas me seguem" (JOÃO $1: 27)$. A batalha contra os surdos ou contra as línguas de sinais é, pois, um empreendimento ao mesmo tempo filosófico e teológico, iniciado em tempos imemoráveis e, por isto mesmo, tão arraigado na cultura do Ocidente. 
Algo correlato, é de se notar, acontece com a chamada semiótica visual. Ao invés de enfrentar o que é próprio da visualidade, trazendo para primeiro plano os processos cognitivos oriundos da imagem, as teorias semióticas autodeclaradas visuais fazem, unicamente, conforme Santos (2014), a aplicação de princípios lógico-formais abstratos e, sobretudo, de pressupostos linguísticos, isto é, verbais, a objetos como desenhos, fotografias ou o cinema.

Aqui, uma primeira tentativa de urdidura. Do mesmo modo que há certa dificuldade ou desinteresse em compreender as línguas de sinais, exclusivamente visuais, em seus próprios termos, existe, também, o indicado fonologocentrismo para abordar a visualidade enquanto linguagem, como pode-se constatar através da consulta a clássicos como "A significação no cinema", de Metz (1972), considerado a base de toda semiótica do cinema, segundo Bellour (2001), e cuja compreensão cinematográfica acontece pelo empréstimo de conceitos fonético/linguísticos organizados binariamente, a exemplo de sintagma/paradigma.

Uma segunda tentativa de urdidura: a noção de cinematografia, concebida por Eisenstein (2002, p. 28-30) como "montagem", definida como a combinação de cenas que são representativas, de significado único e neutras em conteúdo, em contextos e séries intelectuais, através das quais se consegue produzir um "cinema intelectual", talvez seja base para pensar não apenas o cinema em seus próprios termos, mas também as línguas de sinais, cujo princípio é o mesmo do cinema eisensteiniano. A imagem em movimento conceitualmente montada, cujo sentido alicerça-se na própria combinatória visual.

\section{Uma Salvaguarda Conceitual}

Segundo informa Dubois (2004, p. 70-71), a palavra vídeo tem suas raízes etimológicas fincadas no latim videre, "eu vejo", sendo, portanto, o verbo genérico para todas as artes visuais, ao que adicionamos todos os 
processos comunicativos em que a visualidade seja o código ${ }^{1}$ utilizado. Já "grafia", do grego ypapia, designa escrita, ou ainda "cada uma das maneiras de representar por escrito uma palavra" (HOUAISS; VILLAR; FRANCO, 2001, p. 1472), a "forma da letra" (HOUAISS; VILLAR; FRANCO, 2001, p. 1472), compreendendo-se por escrita "um sistema de linguagem composto por uma série limitada, porém diversa, de caracteres que se organizam segundo algumas leis"2 (BORGES, 2005, p. 27).

Neste artigo, portanto, o termo videografia surge como um conceito particular, empregado para nomear toda e qualquer escrita ou registro, isto é, materialização semiótica, operada a partir de signos visuais, por estes entendendo-se estes por mediações visualmente manifestas. Trata-se, logo, de um sentido distinto do usualmente associado à palavra videografia, circunscrita ao universo do vídeo enquanto mídia/arte, cuja emergência se deu na década de 1960 no mundo e de 1970 no contexto brasileiro (MACHADO, 1997, p. 30).

Estabelecida essa definição seminal, podemos, agora, avançar ao objetivo deste artigo ${ }^{3}$ : o de discutir, ainda que amparados por reflexões iniciais, o processo videográfico, ou o processo de uma escrita visual, operado pela língua brasileira de sinais enquanto produção ideogramática em movimento, ao estilo do cinema formal pensado por nomes a exemplo de Eisenstein (2002).

1 O conceito de código é aqui compreendido, conforme define Nöth (1990, p. 206), enquanto instruções para troca de sentidos entre sistemas sígnicos.

2 Mesmo considerando o fato das linguagens terem sido, não raramente, estudadas a partir de registros escritos, muitos linguistas, a exemplo de Bloomfield (apud NÖTH, 1990, p. 251), defendem que "a escrita não seja linguagem, mas apenas uma forma de registrar a linguagem através de marcas visíveis"; isto é, para alguns estudiosos, a escrita não seria um sistema semiótico, mas apenas um modo de materialização da linguagem. Essa não é a perspectiva adotada neste trabalho.

3 Uma primeira versão deste escrito foi apresentada em 2010, na 13a Jornada Peirceana, realizada nas dependências da PUC-SP.

REU, Sorocaba, SP, v. 45, n. 2, D. 429-444, dez. 2019. 


\section{Ideograma}

Calcula-se que as primeiras formas de escrita tenham sido criadas cinco mil anos antes de Cristo, no Oriente Médio, com o objetivo de preservar o pensamento expresso oralmente através da representação de "sílabas, palavras ou frases pronunciadas" (FRUTIGER, 2007, p. 87). A partir de então, segundo Frutiger (2007), teriam se desenvolvido dois tipos distintos de escrita: as figurativas, nas quais o caráter pictogramático encontra-se fortemente preservado, e as alfabéticas, em que os pictogramas são simplificados ao extremo.

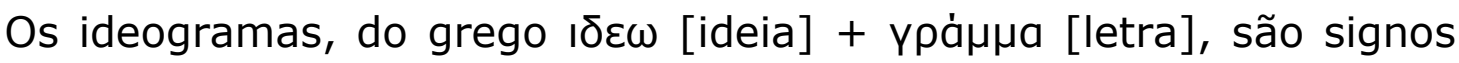
figurativos não fonéticos criados para representar existentes ou ideias, segundo Frutiger (2007), Houaiss; Villar e Franco (2001) e Lupton e Miller (1999), nos quais se destacaria a faceta hipoicônica, relacional, conforme Campos (2000), indo-se no nível imagético e diagramático ao metafórico ao que adicionamos indicial, simbólico e todas as demais classes de signos, conforme Santaella (2004). Tome-se o exemplo da escrita chinesa, mais antiga forma de escrita ideogramática ainda em uso (BORGES, 2005, p. 27),

um sistema preferencialmente inteligível aos olhos, e não aos ouvidos. Cada caractere escrito pode ser compreendido sem que se conheça a sua pronúncia. O chinês, portanto, atua como uma força unificadora em um país no qual, há milênios, as pessoas falam distintos dialetos, dialetos esses ininteligíveis aos seus conterrâneos (CHANG, 1989, p. 40).

Ainda se reportando aos ideogramas chineses - o que talvez possa ser extrapolado a outros alfabetos ideogramáticos -, destaca-se a sua faceta artística. No final da dinastia Han (206 a.C./220 d.C.), surgem os primeiros calígrafos, e no período das Seis Dinastias (220-589 d.C.), "a escrita é convertida na arte dos literatos, como um canal de expressão emocional e intelectual" (CHANG, 1989, p. 47); "cada caractere é um microdesign" (p. 47.), havendo, então, uma grande diversidade criativa, sem, contudo, que sejam desrespeitadas as leis que regem o funcionamento da 
escrita chinesa, responsáveis pela sua capacidade de generalização (BORGES, 2005, p. 29).

\section{A Forma [ideogramática] do Filme}

Muitos estudiosos do cinema, como Pudovkin (apud NÖTH, 1990, p. 264), preocuparam-se com a linguagem cinematográfica. Eisenstein, ainda envolvido com o teatro, segundo Penkala (2008), já começava a se dar conta de que as imagens teatrais em movimento, no palco, eram uma dinâmica do sentido.

Ao estudar a passagem dos hieróglifos ${ }^{4}$ aos ideogramas, Eisenstein (2002, p. 35-36) deu-se conta de que, "pela combinação de duas 'descrições' [visuais] é obtida a representação de algo graficamente indescritível" (EINSENSTEIN, 2002, p. 36). A cópula de dois hieróglifos não resulta em uma soma, mas num "valor de outra dimensão, de outro grau; casa um deles, separadamente, corresponde a um objeto, mas sua combinação corresponde a um conceito" (EISENSTEIN, 2000, p. 151). O desenho da água, combinado ao do olho, cita o cineasta, representa "chorar"; assim, defende Eisenstein, também funcionaria a cinematografia, antes de tudo, montagem: "combinando planos que são descritivos, isolados em significado, neutros em conteúdo - em contextos e séries intelectuais" (EISENSTEIN, 2002, p. 35-36).

Isso parece explicitado na seguinte experiência do cineasta russo Pudovkin, na qual há

[...] a filmagem de um plano do ator Moujoskin com a expressão neutra sendo usada para montagem de três sequências experimentais. Na primeira, o plano foi justaposto a um plano de um prato colocado sobre uma mesa; na segunda, o plano foi articulado ao de um ataúde, no qual jazia uma mulher morta; e na

${ }^{4}$ A palavra "hieróglifo" designa uma "escrita sagrada" [hierós, ícós, é um antepositivo grego para sagrado, divino (HOUAISS; VILLAR; FRANCO, 2001, p. 1531)], e reporta-se a modos de escrita utilizados por povos como os maias e egípcios, nos quais objetos singulares são pictorialmente representados; a união de mais de um hieróglifo origina um ideograma.

REU, Sorocaba, SP, v. 45, n. 2, D. 429-444, dez. 2019. 
terceira, ao plano de uma menina entretida com um brinquedo (LEONE; MOURÃO, 1993, p. 49-50).

Quando as três sequências foram apresentadas, o público esboçou as seguintes reações: elogiou o "ar pensativo" do ator ao contemplar o prato de sopa, sentiu sua tristeza ao lado da mulher morta e admirou o "ligeiro sorriso de felicidade" com que observava a menina brincar. O detalhe era que a expressão do ator era exatamente a mesma nas três situações.

Há, portanto, uma possibilidade de interpretação do cinema enquanto um sistema videográfico ideogramático em movimento, no qual elementos pictóricos são agrupados para a produção dos mais diversos significados, a partir de uma composição sintagmática. Essa concepção será fundamental para o argumento que desenvolveremos a seguir.

\section{A Língua Brasileira de Sinais como Cinema à Eisenstein}

\subsection{Sobre as Línguas de Sinais}

Conforme Nöth (1990), das mãos e braços à postura e aos movimentos, de todos os tipos, o corpo é dotado de grande potencial semiótico. McNeill (2005), apoiado especialmente nos estudos de Kendon, sugere uma divisão em cinco categorias para a linguagem corporal: a 1) gesticulação, movimento que incorpora um significado relacionado ao discurso que acompanha; os 2) gestos associados à fala, movimentos ou expressões que ocupam lugares nas sentenças, trabalhando em conjunto com o discurso oral; os 3 ) emblemas, que são signos convencionais, como o polegar para cima significando "OK"; a 4) pantomima, feita sem auxílio vocal, apenas com movimentos corporais; e, por fim, as chamadas línguas de sinais, segundo Nöth (1990), sistemas semióticos de comunicação gestual com o mesmo potencial das línguas faladas, mas delas independentes.

Esquematicamente, McNeill (2005) propõe a seguinte organização:

- Gesticulação/ Gestos associados à fala: presença obrigatória da fala/sem convenção;

- Emblemas: presença opcional da fala/ parcialmente convencionada 
- Pantomima: falta obrigatória da fala/ sem convenção;

- Linguagem de sinais: falta obrigatória da fala/ totalmente convencionada.

Nosso interesse circunscreve-se, especificamente, conforme Quadros e Karnopp (2004), às línguas de sinais de modalidade gestual-visual ou espaço visual, e dentre elas, à Língua Brasileira de Sinais (LIBRAS), a língua oficial das comunidades surdas brasileiras.

Ferreira Brito (1993 apud RAMOS, 2010, p. 3-4),

aponta os trabalhos de Carrick Mallery, de 1882 (reedidatos por Umiker-Sebeok e Sebeok em 1978, em uma coletânea de dois volumes, com estudos posteriores críticos de outros autores), a respeito das Línguas de Sinais indígenas das Américas e Austrália, como os primeiros estudos lingüísticos sobre Línguas de Sinais. O pesquisador considerava a "Plains Sign Language - PSL/Língua de Sinais das Planícies Norte-Americanas" uma espécie de pantomímica. Apesar disso, porém, seu estudo torna-se importante para o avanço do estudo lingüístico das Línguas de Sinais por apresentar uma descrição bastante completa da PSL, propiciando aos seus sucessores analisar inúmeros aspectos da mesma. 'Alguns estudiosos tais como Voegelin (1958), Liung (1965) e Taylor (1975) analisam a PSL em seus níveis lingüísticos (gestêmico, morfêmico e lexêmico), discutindo os três parâmetros, até então não mencionados neste livro: configuração de mão (forma), movimento ('motion') e ponto de articulação'.

Como, todavia, as Línguas de Sinais indígenas são usadas não só pelos que não ouvem, e especialmente com o fim da comunicação intertribal, convenciona-se datar os primeiros estudos científicos sobre as línguas de surdos como sendo os trabalhos desenvolvidos por Stokoe, a partir de 1957, sobre a ASL, American Sign Language, financiados pelo governo norte-americano (RAMOS, 2010, p. 5) e que renderam o volume "Semiotics and Human Sign Languages" (1972), publicado pela respeitosa De Gruyter Mouton. Sacks (2010, p. 118) chega a dizer que, possivelmente, antes de Stokoe, "nenhum linguista tenha verdadeiramente confrontado a realidade da língua de sinais".

As investigações de Stokoe são de abordagem linguístico-estrutural, e buscam analisar o modo pelo qual os sinais são constituídos, segundo 
Quadros e Karnopp (2004), partindo da hipótese de que as línguas de sinais podem ser assim nomeadas sem recursos metafóricos - são realmente línguas - pois, para Stokoe (1972), substituem símbolos verbais por visuais. Segundo o linguista (STOKOE, 1972, p. 10), há dois grandes malentendidos sobre a linguagem de sinais:

O primeiro é que os gestos humanos são signos universalmente compreendidos. Isto inclui a assunção de que duas pessoas podem se comunicar na mesma língua se ambas conhecem tal língua, mas também inclui a suposição de que se duas pessoas não partilham uma mesma língua elas podem se comunicar 'através de signos'. Essa falácia encontra-se em assumir simplisticamente que gestos humanos sempre denotam a mesma coisa e o mesmo tipo de coisa para qualquer destinatário e que o signo comunica porque os homens são da mesma espécie. Isto conduz à crença de que há uma relação específica entre espécies, simples e constante, entre veículos semióticos gestuais e o que eles denotam - o abanar de cauda de um cachorro é entendido por todos os cachorros. [...]

Quando duas pessoas que não partilham língua comum utilizam a comunicação gestual elas não estão usando a linguagem de sinais. Elas estão fazendo uso ad hoc de certas características de sistemas semióticos. Alguns gestos empregados como signos nestas circunstâncias funcionam como ícones, apresentando similaridade com o que denotam e, quando não apreendidos de imediato, rapidamente captados por tentativa e erro. Alguns gestos - muitos na condição descrita - são índices. Eles apontam para ou são de algum modo contíguos como que exprimem. E alguns gestos são rapidamente entendidos como sinais, por exemplo, signos que controlam ou disparam comportamentos no receptor.

Deste modo, é preciso diferenciar a comunicação por gestos que surge espontaneamente daquela que caracteriza as línguas de sinais. Tanto isto é verdade que, conforme descreve Stokoe (1972), nos jogos para deficientes auditivos onde há pessoas de comunidades surdas oriundas de países diferentes, é necessário realizar interpretação nos vários sistemas de língua de sinais, ou os atletas não entendem as mensagens.

Stokoe (1972) chega à conclusão de que os três princípios que regem a ASL são a (1) configuração de mão, a (2) locação de mão, ou ponto de articulação, e o (3) movimento da mão; seriam essas as unidades mínimas (fonemas) das línguas de sinais (ibid.). Posteriormente, outros estudos, como Quadros e Karnopp (2004), adicionam dois novos elementos à lista de Stokoe: a (4) orientação da mão e os (5) aspectos não manuais dos sinais.

REU, Sorocaba, SP, v. 45, n. 2, p. 429-444, dez. 2019. 
Assim, esquematicamente, podemos compreender as línguas de sinais como constituídas por signos criados a partir da combinação das mãos em movimento, com um determinado formato e em um local específico, local esse que pode ser uma parte do corpo ou do espaço que o margeia. Tais articulações das mãos podem ser comparadas a fonemas e, às vezes, morfemas, e são designadas parâmetros.

Ramos (2010) tipifica para a LIBRAS, conforme abaixo sumarizado, os cinco parâmetros anteriormente citados, originados dos estudos de Stokoe e trabalhos subsequentes:

a) Configuração das mãos: são formas das mãos, que podem ser da datilologia (alfabeto manual) ou outras formas feitas pela mão predominante (mão direita para os destros), ou pelas duas mãos do emissor ou sinalizador. Os sinais "aprender", "laranja" e "adorar" têm a mesma configuração de mão;

b) Ponto de articulação: é o lugar onde incide a mão predominante configurada, podendo esta tocar alguma parte do corpo ou estar em um espaço neutro vertical (do meio do corpo até à cabeça) e horizontal (à frente do emissor). Os sinais "trabalhar", "brincar", "consertar" são feitos no espaço neutro, e os sinais "esquecer", "aprender" e "pensar" são feitos na testa;

c) Movimento: os sinais podem ter um movimento ou não. Os sinais citados acima têm movimento, com exceção de "pensar" que, como os sinais "ajoelhar", "de pé", não têm movimento;

d) Orientação: os sinais podem ter uma direção e a inversão desta pode significar ideia de oposição, contrário ou concordância número-pessoal, como os sinais "querer" e "querer-não"; "ir" e "vir";

e) Expressão facial e/ou corporal: muitos sinais, além dos quatro parâmetros mencionados acima, em sua configuração têm como traço diferenciador também a expressão facial e/ou corporal, como os sinais "alegre" e "triste". Há sinais feitos somente com a bochecha como "ladrão", "ato-sexual".

É na combinação dos parâmetros a, b, c, e d, aos quais pode estar adicionada uma expressão corporal e/ou facial, que se constrói o sinal, signo visual com poder representativo não apenas icônico, mas também indicial e metafórico; na verdade, acreditamos que através da língua de sinais seja possível criar signos de todos os tipos: consegue-se discutir de religião a futebol, apontar-se fatos concretos e imaginários ou ainda expressar 
sentimentos, isto é, caminhar-se da concretude à abstração, assim como no discurso oral.

Cada gesto, isoladamente, talvez possa ser compreendido enquanto ideograma. Os sinais emitidos no e com o corpo são, exatamente, signos figurativos e não fonéticos, capazes de representar conceitos - inclusive conceitos abstratos. Por isso, a nossa proposta em perceber as línguas de sinais, entre as quais a LIBRAS, ao modo de uma composição ideogramáica, na qual se destaque, conforme se processa na escrita chinesa, a faceta "artística", traduzida no sentimento e na criatividade que cada falante emprega, de modo único, através do seu corpo.

Uma peculiaridade, contudo, diferencia estruturalmente as línguas de sinais das faladas. Além de serem visuais, e não sonoras, elas, precisamente por esse fato, não são, apenas, temporalmente lineares. Ao invés de cada fonema - que às vezes é um morfema, unidade mínima de significado - ser pronunciado em separado, após o seu antecessor, como ocorre no som, a visualidade permite que os fonemas sejam articulados simultaneamente, no que Hulst (apud QUADROS; KARNOPP, 2004, p. 49) assim esquematiza:

a) Língua Oral

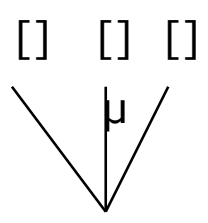

b) Língua de Sinais

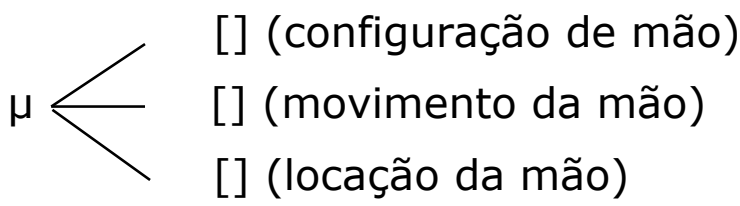

Sucessão horizontal = sucessão temporal

Alinhamento vertical $=$ simultaneidade temporal

$\mu=$ morfema

REU, Sorocaba, SP, v. 45, n. 2, D. 429-444, dez. 2019. 
[] = um fonema ou conjunto de especificações

Isso nos leva a pensar que, se comparada às imagens técnicas, a LIBRAS e as demais línguas de sinais estejam, de fato, relacionadas ao cinema, sobretudo ao "cinema intelectual" de Eisenstein.

\subsection{Imagens Simultâneas em Movimento}

Stokoe (apud SACKS, 1989, p. 106) propõe uma espécie de "composição cinematográfica" na gestualidade empregada pelas línguas de sinais, onde se identificariam elementos como o close, campo de visão e ângulos que dirigiriam o olhar do receptor. Se, conforme sugerimos, a LIBRAS possa ser tomada como uma linguagem ideogramática e, como queria Eisenstein, o cinema for uma composição sequencial de ideogramas, a proposta de Stokoe nos parece razoável.

A questão é complexa: ao mesmo tempo em que os ideogramas se sucedem, para se edificarem, eles unem simultaneamente variados fonemas (os hieróglifos citados por Eisenstein). Não por acaso, Sacks (2010, p. 87) chega a localizar, entre os falantes de línguas de sinais, uma "habilidade para separar configurações descontínuas, ou 'quadros', de um fluxo contínuo de movimento"; assim como os ouvintes, conforme Sacks (2010), conseguem decompor e analisar a fala a partir de um padrão contínuo, porém mutável de ondas sonoras, os deficientes auditivos seriam dotados da capacidade cognitiva de operar o mesmo processo visualmente.

Defendemos, pois, que a videografia - escrita visual - resultante da expressão nas línguas de sinais, inclusive na LIBRAS, possa ser compreendida a partir dos princípios pensados por Eisenstein para o cinema: elementos visuais ideogramáticos em movimento combinados, simultânea e sequencialmente, para a geração dos mais diversos processos cognitivos, capazes não apenas de expressar sentidos correlatos aos criáveis com a linguagem sonora/verbal, mas também sentidos próprios, sem correlatos linguísticos.

REU, Sorocaba, SP, v. 45, n. 2, D. 429-444, dez. 2019. 


\section{Considerações Finais}

A partir do percurso por realizado, acredita-se encontrar, ainda que de modo inicial, bases para propor que a LIBRAS, e outras línguas de sinais, sejam constituídas como ideogramas cinéticos. São gestos, expressões e movimentos com o poder de gerar os mais distintos signos, não apenas individualmente, como no "micro-design" de cada ideograma chinês, mas especialmente em sequência, a partir dos hábitos semióticos que regulam a composição dos parâmetros das línguas de sinais, parâmetros estes diversos dos operados nas línguas verbais/sonoras.

Desse modo, sugerimos que o registro das línguas de sinais seja videografado tal qual elas são expressas: em movimento. Por isso, no decorrer de nosso texto, evitamos trazer exemplos ilustrativos estáticos, como é comum de se encontrar nos dicionários de línguas de sinais e, por exemplo, no citado volume American Sign Language, escrito por Stokoe (1972, p. 33), (Figura 1):

Figura 1 -Registro estático de Língua de Sinais

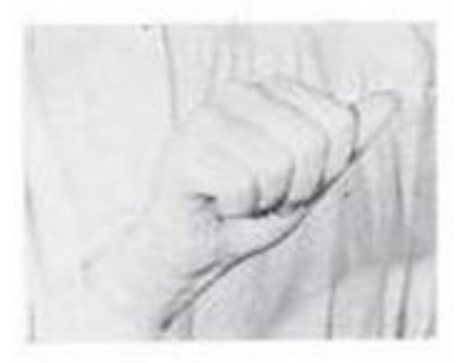

Tab 0 Dez A

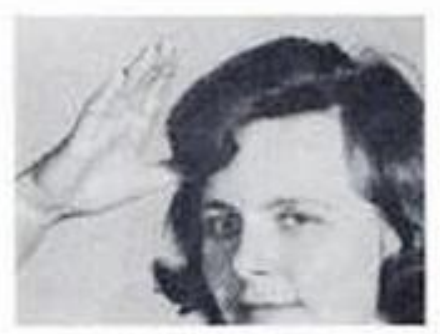

Tab ${ }^{n}$ Dox 5

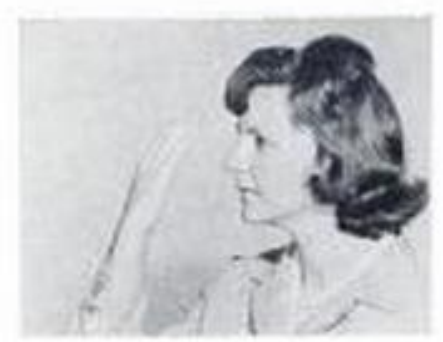

Tab 0 Dex $\theta_{4}$

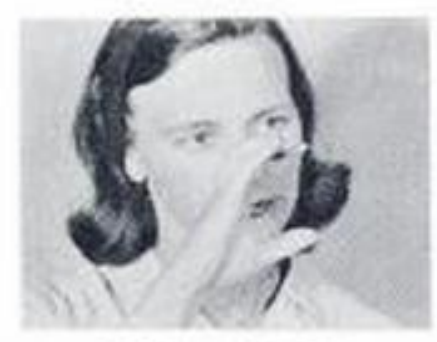

Tab a Dez C

Fonte: STOKOE, William. Semiotics and human sign languages. Ghent: Mouton de Gruyter, 1972. 
Pensar sobre este registro das línguas de sinais é um problema semiótico retórico, isto é, preocupado com as condições necessárias para a troca de signos entre mentes - a geração de interpretantes, segundo Bergaman (2007), ou os signos que os signos produzem ou podem vir a produzir, conforme Santaella (2004). Ao se transportar o universo do movimento para o quadro a quadro impresso, elementos fundamentais de linguagens como a LIBRAS são perdidos, especialmente considerando o fato de os surdos terem uma percepção distinta da dos ouvintes para signos visuais.

Se, como sugerem pesquisas empíricas, a visão é responsável, para alguém sem deficiência sensorial, por algo em torno de $75 \%$ a $80 \%$ de tudo percebido, conforme Amiralian (1997) e Santaella (1998), é possível que essa percentagem seja ainda maior para pessoas surdas, e que elas sejam dotadas de capacidades cognitivas próprias; assim indicam estudos, conforme Sacks (2010), cujos resultados demonstram a realocação, no cérebro, de áreas predominantemente auditivas, como o lobo temporal esquerdo, para o processamento visual.

Por isso, finalizamos o texto indicado que, doravante, a LIBRAS e as línguas de sinais, de modo genérico, sejam registradas o mais próximo possível de seu objeto dinâmico, ou daquilo que elas tentam representar. Elas devem ser videografadas em movimento, permitindo a gravação de cada ideograma corporal em todo o seu potencial semiótico, assim como das composições ideogramáticas criadas; o cinema, de fato, nos parece uma sugestão adequada a este intento.

Muir e Richardson (2005) parecem corroborar da nossa proposta e indicam certos protocolos. Ao examinar a influência dos vídeos com conteúdo de linguagem de sinais sobre os mecanismos de atenção de espectadores surdos, os autores chegaram a conclusões importantes:

a) A face tem um papel fundamental para que a gestualidade ganhe sentido. Certa medida, expressões faciais e movimentos labiais dão "pistas" para 
uma correta interpretação do gesto realizado; isto é, rosto e gestualidade precisam ser vistos ao mesmo tempo quando se fala em LIBRAS;

b) Por isto, ao se videografar uma mensagem em língua de sinais, deve-se manter uma alta resolução na área que corresponde à face, enquanto os gestos podem ter resolução reduzida.

Tal conhecimento pode ajudar a se criar filtros específicos capazes de produzir imagens mais "leves", de alta resolução apenas onde se faz necessário, para que se transmitam mensagens em línguas de sinais LIBRAS incluída - de modo eficiente.

\section{Referências}

AMIRALIAN, Maria Lúcia T. M. Compreendendo o cego: uma visão psicanalítica da cegueira por meio de Desenhos-Estórias. São Paulo: Casa do Psicólogo, 1997. BELLOUR, Raymonds. The analysis of film. Bloomington: Indiana University Press, 2001.

BÍBLIA. Português. Bíblia sagrada: antigo e novo testamento. Tradução de João Ferreira de Almeida. Edição rev. e atualizada no Brasil. Brasília: Sociedade Bíblia do Brasil, 1969.

BORGES, Priscila. Tipografia: Ideograma ocidental. 2005. 278 f. Dissertação (mestrado em Comunicação e Semiótica) - Programa de Pós-graduação em Comunicação e Semiótica, Pontifícia Universidade Católica de São Paulo, São Paulo, 2005.

CAMPOS, Haroldo. Fenellosa Revisitado. In: CAMPOS, Haroldo (org.).

Ideograma: lógica, poesia, linguagem. São Paulo: EdUsp, 2000.

CHANG, Cheng-Mei. Chinese writing: a system of characters rich in structural diversity. Expedition, Philadelphia, v. 31, n. 1, p. 40-51, 1989. Disponível em: https://www.penn.museum/sites/expedition/chinese-writing/. Acesso em: 16 dez. 2019.

DERRIDA, Jacques. Gramatologia. São Paulo: Perspectiva / EdUsp, 1973.

DUBOIS, Philippe. Cinema, video, Godard. São Paulo: Cosac Naify, 2004.

EISENSTEIN, Serguei. A forma do filme. Rio de Janeiro: Jorge Zahar, 2002.

EISENSTEIN, Serguei. O princípio cinematográfico e o ideograma. In: CAMPOS, Haroldo [org.]. Ideograma: lógica, poesia, linguagem. São Paulo: EdUsp, 2000.

FERREIRA BRITO, Lucinda. Integração social \& educação de surdos. Rio de Janeiro: Babel, 1993.

FRUTIGER, Adrian. Sinais e símbolos: desenho, projeto e significado. São

Paulo: Martins Fontes, 2007.

HOUAISS, A.; VILLAR, M. DE S.; FRANCO, F. M. DE M. Dicionário Houaiss da língua portuguesa. Rio de Janeiro: Objetiva, 2001. 
LEONE, Eduardo; MOURÃO, Maria D. G. Cinema e montagem. São Paulo: Ática, 1993.

LUPTON, Ellen; MILLER, J. Abbott. Design writing research. Londres: Phaidon, 1999.

JOÃO. In: Bíblia. Português. Bíblia sagrada: antigo e novo testamento.

Tradução de João Ferreira de Almeida. Edição rev. e atualizada no Brasil.

Brasília: Sociedade Bíblia do Brasil, 1969.

MACHADO, Arlindo. Pré-cinemas \& pós-cinemas. Campinas: Papirus, 1997.

MCNEILL, David. Gesture and thought. Chicago: University of Chicago, 2005.

METZ, Christian. A significação no cinema. São Paulo: Perspectiva, 1972.

MUIR, Laura J.; RICHARDSON, Iain E. G. Perception of Sign Language and Its Application to Visual Communications for Deaf People. Journal of Deaf Studies and Deaf Education, Oxford, v. 10, n. 4, p. 390-401, 2005. Disponível: https://academic.oup.com/jdsde/article/10/4/390/363394. Acesso: 16 dez. 2019.

NÖTH, Winfried. Handbook of semiotics. Bloomington e Indianapolis: Indiana University, 1990.

PENKALA, Ana Paula. Eisenstein e os ideogramas japoneses. Analisando a montagem intelectual. Biblioteca On-line de Ciências da Comunicação, Covilhã, Portugal, p. 1-9, 2008. Disponível em:

http://www.bocc.ubi.pt/pag/penkala-ana-paula-eisenstein-ideogramaschineses.pdf. Acesso em: 16 dez. 2019.

QUADROS, Ronice; KARNOPP, Lodenir. Língua de sinais brasileira: estudos lingüísticos. Porto Alegre: Artmed, 2004.

RAMOS, Clélia. Libras: a língua de sinais dos surdos brasileiros. Disponível em: http://www.editora-arara-azul.com.br/pdf/artigo2.pdf. Acesso em: 10 abr. 2010.

SACKS, Oliver. Vendo vozes: uma jornada pelo mundo dos surdos. Rio de Janeiro: Imago, 1990.

SACKS, Oliver. Vendo vozes: uma jornada pelo mundo dos surdos. São Paulo: Companhia das Letras, 2010.

SANTAELLA, Lucia. A percepção: uma teoria semiótica. São Paulo:

Experimento, 1998.

SANTAELLA, Lucia. A teoria geral dos signos: como as linguagens significam as coisas. São Paulo: Pioneira Thomson Learning, 2004.

SANTOS, Marcelo. Sobre a aplicação da semiótica à comunicação visual: algumas questões epistemológicas. Revista Fronteiras (Online), São Leopoldo, RS, v. 16, p. 132-143, 2014. Disponível em:

http://revistas.unisinos.br/index.php/fronteiras/article/view/fem.2014.162.07. Acesso em: 16 dez. 2019.

SKLIAR, Carlos. Uma análise preliminar das variáveis que intervêm no Projeto de Educação Bilíngüe para os Surdos. Espaço Informativo Técnico Científico do INES, Rio de Janeiro, v. 6, p. 49-57, 1997.

STOKOE, William. Semiotics and human sign languages. Ghent: Mouton de Gruyter, 1972.

REU, Sorocaba, SP, v. 45, n. 2, D. 429-444, dez. 2019. 